\title{
STUDENTS' PERCEPTION OF ORGANIZATION CULTURE AT A FACULTY OF SCIENCE AND TECHNOLOGY
}

\author{
Ujhelyi Maria associate professor \\ University of Debrecen Faculty of Economics and Business \\ e-mail: ujhelyi.maria@econ.unideb.hu
}

Kun Andras Istvan associate professor

University of Debrecen Faculty of Economics and Business

e-mail: kun.andras.istvan@econ.unideb.hu

Hanesz Julia BSc. student

University of Debrecen Faculty of Economics and Business, DEX Workshop, Karoly

Ihrig College for Advanced Studies

e-mail: hanesz.julia@gmail.com

(Received: February 2017; Accepted: April 2017)

\begin{abstract}
The current study uses an adapted version of Cameron and Quinn's OCAI questionnaire to test the organisational culture of the Faculty of Science and Technology at the University of Debrecen, Hungary, as it is perceived by its students, and also to discover what type of organisational culture the same students think would be ideal for them. An additional objective of this paper is to identify possible gaps between the perceived and the ideal cultures expressed by the students. Our sample includes 128 questionnaires completed by bachelor students from 6 different majors at the faculty. According to our results, the respondents perceive to a significant degree that the faculty's organisational culture is at an average level of clan, market and hierarchy cultures, while it also exhibits a relatively low level of the adhocracy culture. Their ideal faculty culture would be one with average adhocracy, average hierarchy, high clan and low market features. Significant gaps are identified between the perceived and ideal cultures in all the four types: students would prefer an increase in clan and adhocracy cultures, and a decrease in the other two cultures.

Keywords: organizational culture, higher education, Competing Values Framework, Organizational Culture Assessment Instrument (OCAI)
\end{abstract}

J.E.L. CODES: M14, I23

\section{Introduction}

Organizational culture is ever-present and exists in every organization. Several empirical studies have found evidence of the significant impact of culture on organizational performance (Martinez et al, 2015). Our study is part of a research series at a Hungarian higher educational institution - the University of Debrecen (UD) - which aims to examine the organizational culture as students perceive it. In 
our research we used a widely accepted culture diagnostic method: the Organizational Culture Assessment Instrument (OCAI). This is a questionnairebased instrument, invented for the Competing Values Framework (CVF), and developed by Cameron and Quinn (2006). Over the course of the research series, data have been and will be collected from different faculties of the UD. So far, only the data from the technical manager BSc students from the Faculty of Engineering (hereinafter UD-FE) have been analysed (Ujhelyi\&Kun, 2016). In this paper, bachelor students on many different majors from the Faculty of Science and Technology (UD-FST) will be examined with similar methods. Therefore, we will be able not only to answer our main research questions, but also to compare the results of the two faculties. Our research questions are:

1. How do the students categorize the organizational culture of the Faculty of Science and Technology at the University of Debrecen, Hungary, according to the Competing Values Framework?

2. According to the students, is there a significant gap between the preferred and perceived organizational culture of the UD-FST? If there is, how can this gap be described?

\section{Literature review}

Peters and Watermann (1982) were among the first to draw attention to the role of culture in influencing organizational success, and began to examine it from different perspectives. Schein (1985) defined the levels, while Robbins (2005) described the characteristics, of culture. Several different models of organizational culture were developed (Covin\&Slevin, 1990; Handy, 1993; Cameron\&Quinn, 2006), because authors focused on different values in their inquiries (Bakacsi, 2015).

According to Schein $(2004$, p. 17) "...the culture of a group can be defined as a pattern of shared basic assumptions that was learned by a group as it solved its problems of external adaptation and internal integration, that has worked well enough to be considered valid and, therefore, to be taught to new members as the correct way to perceive, think, and feel in relation to those problems." This definition is an appropriate explanation of what was emphasised by the "Competing Values Framework" (CVF) proposed by Quinn and Rohrbaugh (1983). The CVF was originally developed in the context of research examining indicators of effective organizations. Campbell et al (1974) created a list of 39 indicators which, in their view, defined organizational effectiveness. Quinn and Rohrbaugh (1983) conducted factor analysis on these indicators and organized them into four major factors along two dimensions. The first dimension consisted of the dichotomy of two efficiency criteria: one emphasised flexibility, insight and 
dynamism; the other accented stability, order and control. At one extreme of the other dimension is internal orientation, comprising efficiency indicators which highlight unity and understanding, while at the other extreme is external orientation, with efficiency indicators which highlight outward focus, differentiation and competition.

When the two dimensions were placed together, four distinct sets of efficiency indices emerged, indicating what people value in organizational performance, and what they consider to be good, accurate and appropriate. More specifically, the four different sets of criteria define the core values that guide organizational decisions. In a coordinate system stretched along the two dimensions this value appears as four quarters (see Figure 1): clan (one dimension features internal focus and integration, the other flexibility and independence), hierarchy (internal focus and integration - stability and control), market (external focus and differentiation stability and control) and adhocracy (external focus and differentiation - flexibility and independence). This model does not suggest that organizations fit precisely into only one of the quarters (these quarters later will be called culture types), nor that one quarter is better than the others, but it does state that there is a tension among them (Senior\&Swailes, 2010).

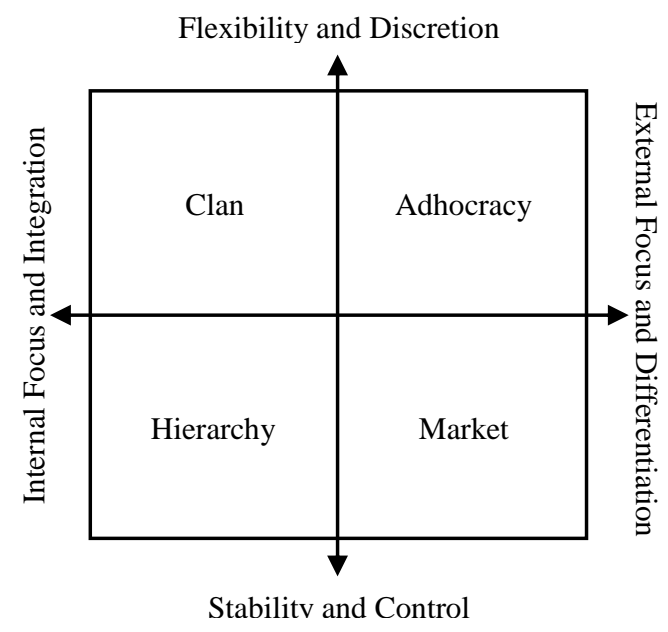

Figure 1. The Competing Values Framework Source: Cameron\&Quinn, 2006, p. 35.

Cameron and Quinn (2006) also found that the four quarters resulting from the analysis fit accurately to four types of organizational structures defined by 
Ujhelyi M., Kun A.I., Hanesz J. (2017)

Students' perception of organization culture at a Faculty of Science and Technology

organization theories, as well as to management theories known from organizational theory, and also to approaches to understanding organizational quality, leadership roles and management skills.

The Organizational Culture Assessment Instrument (OCAI) is an organizational culture assessment questionnaire based on the CVF (Cameron\&Quinn, 2006). Over the years, several extended variants of the questionnaire have been developed, but the parsimonious version, which consists of six times four, i.e. a total of 24 statements, was found to describe the organizational culture no less appropriately than the longer versions. This instrument is a suitable method of determining the current culture (referred to as 'now' in the OCAI) as described by organizational members and also of defining the ideal culture (referred to as 'preferred' which fits future environmental needs and organizational opportunities.

The OCAI consists of six parts, which are also referred as dimensions. It must be noted that the OCAI's six dimensions do not correspond to the CVF's two dimensions. These parts, or dimensions, are the following: (1) dominant characteristics, (2) organizational leadership, (3) management of employees, (4) organization glue, (5) strategic emphases, and (6) criteria of success. In each part respondents have to distribute 100 points among four alternative statements, depending on how much they fit the respondents' organization (Fralinger\&Olson, 2007). The four alternative statements in a given dimension represent the four culture types: hierarchy, clan, adhocracy and market.

Using OCAI in cultural analysis is quite common. More than one thousand organizations had already used it before the appearance of the questionnaire our study is based on (Cameron\&Quinn, 2006); and it has also been successfully applied in the examination of university cultures (Fralinger\&Olson, 2007; Shirbagi, 2007).

\section{Material and methods}

The empirical part of this paper is based on primary survey data. Cameron and Quinn's (2006) OCAI questionnaire was slightly modified by the researchers, working together with masters students during seminars. The last dimension was removed from the original six-dimensional questionnaire due to its irrelevance (the sixth dimension asked about the organization's success criteria from an employee's point of view, something that students cannot be aware of, thus leaving it in the questionnaire would have led to random or biased answers). Therefore, the modified OCAI questionnaire contained 5 times (5 dimensions) 4 statements (4 alternatives), totalling 20 items, together with some additional, mainly demographic questions, created for this specific survey (see Table 1 in the appendix). The five times four items corresponded to four culture types (clan $-\mathrm{A}$, 
adhocracy - B, market $-\mathrm{C}$, hierarchy $-\mathrm{D}$ ). Respondents had to distribute 100 points among 4 statements per dimension, awarding more points for statements they considered more appropriate. In the evaluation process, the scores belonging to the 5 statements for each culture type were averaged to obtain the overall scores for each culture type. Respondents were asked to assess both the current ('now') culture and the one they perceive to be ideal ('preferred'). For a detailed presentation of the original questionnaire in Hungarian, see the study by Ujhelyi and Kun (2016).

The survey was conducted in December 2015, in the framework of the course "General economics and management studies" taken by bachelor students from the Faculty of Science and Technology, University of Debrecen (UD-FST). The participation was voluntary and anonymous.

200 questionnaires were at least partially answered (the number of students in the course was 235), but incomplete or incorrectly answered questionnaires were excluded from the study (for example, when more, or less, than 100 points were distributed among the four alternative statements in any of the dimensions). Questionnaires connected to years and semesters with an insufficient number of students were also excluded from the analysis. The size of the sample finalized in this way was 128, 109 of whom began their studies in the autumn semester of 2014 (44 male, 65 female), and 19 in the autumn of 2015 (10 male, 9 female) at UDFST. The permanent place of residence of 28 respondents was Debrecen (the city of the UD). Based on these responses, 97 students lived in a city or in a town, and 27 in a village. According to the responses, the year of birth ranged between 1981 and 1997. The estimated average age of respondents was 20.97 years (the standard deviation was 1.90 years), which was estimated from the difference between the year of birth and the date of the survey. The median age was 20.46 years. Students reported studying the following majors: 61 studying Biology, 21 Chemistry, 18 Geography, 14 Geology, 12 Mathematics, 1 Environmental Sciences, and 1 who did not respond. Majors with a low representation were not excluded from the sample, since there is a great overlap among them from the cultural perspective (e.g. instructors, study office, common courses). Our analysis is based on simple statistical methods: descriptive statistics, one-sample $t$-tests and paired-sample $t$ tests.

\section{Results}

Based on the data collected through the questionnaire survey described above which was non-representative but provided a relatively large sample size - we were able to estimate the students' perceptions of the organizational culture of the Faculty of Science and Technology at the University of Debrecen. OCAI 
Ujhelyi M., Kun A.I., Hanesz J. (2017)

Students' perception of organization culture at a Faculty of Science and Technology

questionnaire results are traditionally presented via web-diagrams (Fig. 2), but to better support a more rigorous analysis, the necessary numerical information is also shown in Table 2, together with some of the test outcomes, described below in detail.

Overall
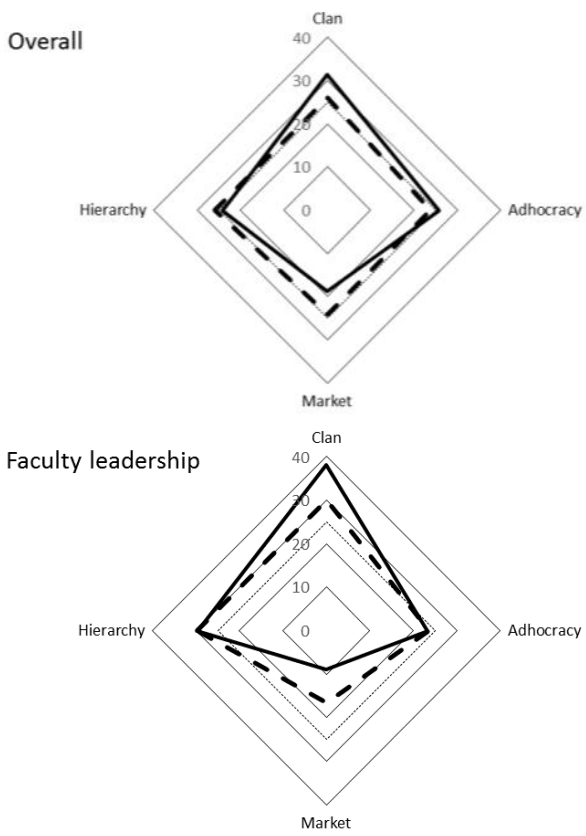

Organization glue

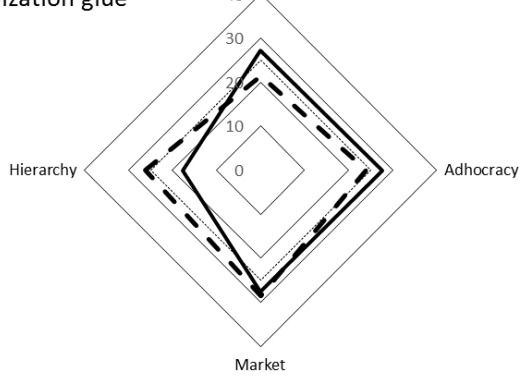

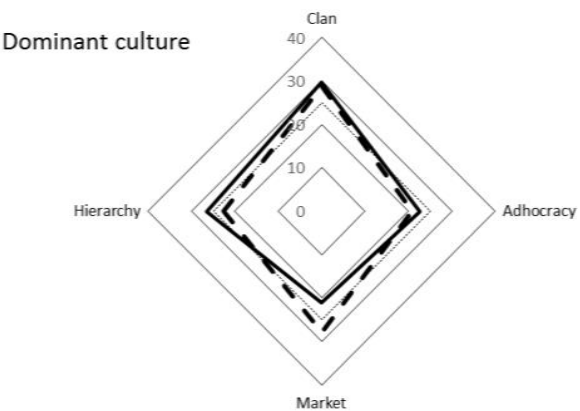

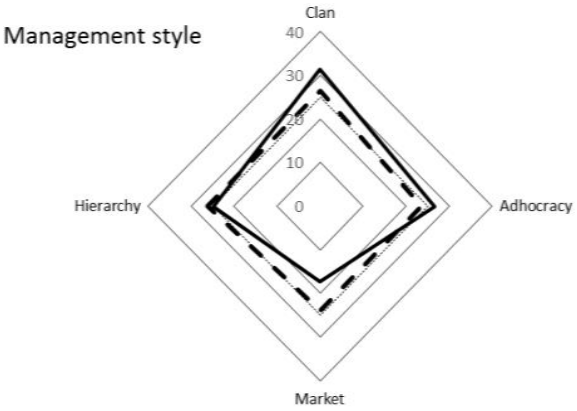

Faculty emphases

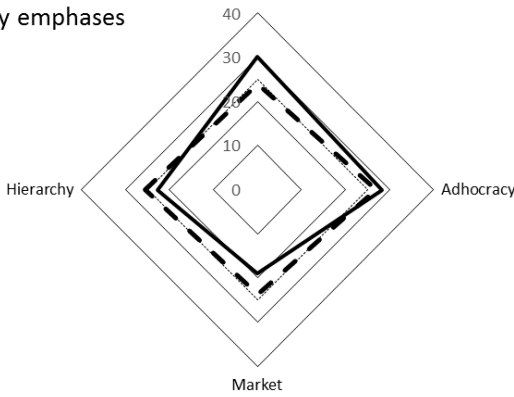

Figure 2. Web-diagram of the culture(s) perceived and preferred by the students Note: dashed lines represent the 'now' culture, solid lines represent the 'preferred' culture. Source: primary research 


\subsection{The organizational culture of the faculty as students perceive it}

According to the average of the sample, the present ('now') culture was perceived by students to be significantly different (at the 5\% level) from 25 - the expected value of a culture perfectly balanced in the competing values -, when answering 9 of the 20 statements (i.e. $45 \%$ ). See Table 2 for the data of the one-sample $t$-tests.

Table 2. Values of OCAI dimensions and organizational culture types

\begin{tabular}{|c|c|c|c|c|c|c|c|c|}
\hline \multicolumn{2}{|l|}{$\begin{array}{l}\text { Dimension; } \\
\text { culture-type }\end{array}$} & \multicolumn{3}{|c|}{ 'Now' culture } & \multicolumn{3}{|c|}{ 'Preferred' culture } & \multirow{2}{*}{\begin{tabular}{|c|} 
Difference \\
$t$
\end{tabular}} \\
\hline & $\mathrm{T}$ & Mean & S.D. & $t$ & Mean & S.D. & $t$ & \\
\hline \multirow{4}{*}{$\begin{array}{l}\text { 1. Dominant } \\
\text { characteristics }\end{array}$} & A & 28.77 & 16.20 & $2.63^{* * 4}$ & 29.77 & 13.76 & $3.92^{* *}$ & 0.83 \\
\hline & $\mathrm{B}$ & 20.77 & 11.23 & $-4.27^{* * * *}$ & 22.54 & 11.19 & $-2.49^{* *}$ & 1.52 \\
\hline & $\mathrm{C}$ & 27.92 & 15.42 & $2.14^{* * *}$ & 21.17 & 10.17 & $-4.26^{* * * *}$ & $-5.04^{* * * *}$ \\
\hline & $\mathrm{D}$ & 22.55 & 11.16 & $-2.49^{* *}$ & 26.52 & 11.48 & 1.50 & $3.23^{* * *}$ \\
\hline \multirow{4}{*}{$\begin{array}{l}\text { 2. Faculty } \\
\text { leadership }\end{array}$} & $\mathrm{A}$ & 29.99 & 14.66 & $3.85^{* * * *}$ & 38.10 & 14.58 & $10.16^{\text {**** }}$ & $6.51^{\text {**** }}$ \\
\hline & B & 23.63 & 9.79 & -1.58 & 23.26 & 7.96 & $-2.48^{* * *}$ & -0.43 \\
\hline & $\mathrm{C}$ & 16.59 & 16.19 & $-5.87^{\text {***** }}$ & 8.99 & 9.21 & $-19.67^{* * * *}$ & $-6.20^{* * * *}$ \\
\hline & $\mathrm{D}$ & 29.78 & 12.14 & $4.45^{* * *}$ & 29.65 & 10.41 & $5.05^{* * * *}$ & -0.12 \\
\hline \multirow{4}{*}{$\begin{array}{l}\text { 3. Management } \\
\text { style }\end{array}$} & $\mathrm{A}$ & 26.37 & 12.85 & 1.20 & 31.30 & 11.98 & $5.95^{* * * *}$ & $4.70^{* * * * *}$ \\
\hline & $\mathrm{B}$ & 23.59 & 11.26 & -1.41 & 26.66 & 8.56 & $2.19^{* * *}$ & $2.60^{* * * *}$ \\
\hline & $\mathrm{C}$ & 23.91 & 15.36 & -0.81 & 17.23 & 10.51 & $-8.36^{* * * *}$ & $-5.03^{* * * *}$ \\
\hline & $\mathrm{D}$ & 26.13 & 13.46 & 0.95 & 24.81 & 8.73 & -0.24 & -1.13 \\
\hline \multirow[t]{4}{*}{ 4. Organization glue } & $\mathrm{A}$ & 21.34 & 11.21 & $-3.70^{* * * * *}$ & 27.20 & 10.13 & 2.45 & $6.26^{* * * * *}$ \\
\hline & $\mathrm{B}$ & 23.89 & 11.30 & -1.11 & 27.70 & 10.07 & $3.03^{* * * *}$ & $3.76^{* * * *}$ \\
\hline & $\mathrm{C}$ & 28.56 & 13.71 & $2.94^{* * * *}$ & 27.52 & 10.43 & $2.73^{* * *}$ & -0.95 \\
\hline & $\mathrm{D}$ & 26.21 & 16.29 & 0.84 & 17.59 & 8.24 & $-10.17^{* * * *}$ & $-5.99^{* * *}$ \\
\hline \multirow[t]{4}{*}{ 5. Faculty emphases } & $\mathrm{A}$ & 23.91 & 12.26 & -1.01 & 30.08 & 11.05 & $5.20^{* * * *}$ & $5.55^{* * * *}$ \\
\hline & B & 26.84 & 12.59 & $1.66^{*}$ & 28.20 & 9.28 & $3.91^{* * * *}$ & 1.29 \\
\hline & $\mathrm{C}$ & 23.66 & 13.42 & -1.13 & 18.90 & 9.97 & $-6.92^{\text {**** }}$ & $-3.60^{* * *}$ \\
\hline & $\mathrm{D}$ & 25.59 & 13.28 & 0.50 & 22.82 & 8.44 & $-2.92^{* * * *}$ & $-2.12^{* * *}$ \\
\hline \multicolumn{2}{|l|}{ (A) Clan } & 26.07 & 8.25 & 1.47 & 31.29 & 7.19 & $9.89^{\cdots \cdots \cdots}$ & $8.94^{2 * \pi \%}$ \\
\hline \multicolumn{2}{|l|}{ (B) Adhocracy } & 23.75 & 6.45 & $-2.20^{* * * *}$ & 25.67 & 4.44 & $1.71^{*}$ & $3.44^{\text {**:* }}$ \\
\hline \multicolumn{2}{|l|}{ (C) Market } & 24.13 & 9.30 & -1.06 & 18.76 & 6.30 & $-11.21^{* * * *}$ & $-7.21^{* * * 3}$ \\
\hline \multicolumn{2}{|l|}{ (D) Hierarchy } & 26.05 & 6.82 & $1.75^{*}$ & 24.28 & 4.80 & $-1.70^{*}$ & $-2.83^{* * *}$ \\
\hline
\end{tabular}

Notes: In the 'now' and 'preferred' culture columns, $t$ indicates the one-sample $t$ test, while in the 'difference' column it represents the paired-samples $t$-test. " significant at the $10 \%$ level, ${ }^{* *}$ significant at the $5 \%$ level, ${ }^{* * *}$ significant at the $1 \%$ level; $\mathrm{T}=$ culture type, where $\mathrm{A}=$ clan, $\mathrm{B}=$ adhocracy, $\mathrm{C}=$ market, $\mathrm{D}=$ hierarchy; $N=128$. Source: primary research

DE GRUYTER OPEN
Studia Universitatis "Vasile Goldis" Arad. Economics Series Vol 27 Issue 1/2017 ISSN: 1584-2339; (online) ISSN: 2285 - 3065 
All of the previously mentioned 9 items were connected to three dimensions of the five: 'dominant characteristics', 'organizational leadership', and 'organization glue'. The students identified the culture of their faculty as above-average $(>25)$ in the following:

- dominant characteristics: informal and family-like (1A), competitive, job- and results-oriented (1C),

- behaviour of the faculty staff and the management: mentoring, facilitating (2A), coordinating and cooperating (2D);

- the glue holding the faculty together: emphasis on achievement and goal accomplishment $(4 C)$.

At the same time, the 'now' culture was perceived to be below-average $(<25)$ in:

- dominant characteristics: dynamic and entrepreneurial, willingness to take risks $(1 B)$, controlled and structured (1D),

- behaviour of the faculty staff and the management: aggressive and resultsoriented $(2 C)$,

- the glue holding the faculty together: loyalty and mutual trust (4A).

According to the four culture types (calculated as the mean of the statements' values connected to the given type) only the adhocracy showed a significant difference from 25, indicating that students feel the culture of the Faculty of Science and Technology is palpably low in adaptation, flexibility and innovation/creativity.

\subsection{The culture that students would prefer}

The 'preferred' culture had much stronger features than the 'now' culture. The former was found to be significantly different from a neutral culture (again, represented by the value 25) by students when answering 18 statements (90\%). In other words, there were only two questions where the average value of the ideal culture was not significantly different from 25 (see Table 2). According to the answers, the ideal culture would be above-average ( $>25$ ) in the following features:

- dominant characteristics: informal and family-like (1A),

- behaviour of the faculty staff and the management: mentoring, facilitating (2A), coordinating and cooperating $(2 D)$;

- management style: teamwork, and participation (3A), innovation, freedom and uniqueness (3B),

- the glue holding the faculty together: loyalty and mutual trust (4A), commitment to innovation and development (4B), emphasis on achievement and goal accomplishment (4C),

- strategic emphases: human development, trust, and participation (5A), acquiring new opportunities, resources and coping with new challenges (5B). 
Students expressed the opinion that a below-average $(<25)$ level would be ideal in the following features:

- dominant characteristics: dynamic and entrepreneurial, willingness to take risks (1B), competitive, job- and results-oriented (1C),

- behaviour of the faculty staff and the management: exemplify entrepreneurship, innovation (2B), aggressive and achievement-oriented (2C),

- management style: hard-driving competitiveness, and achievement (3C),

- the glue holding the faculty together: formal rules and regulations (4D),

- strategic emphases: competitive actions and achievement (5C), permanence, stability, efficiency and control (5D).

In terms of the aggregated culture-types, the students would prefer the clan culture to be significantly above, and the market culture significantly below, the neutral level (see Table 2).

\subsection{Analysing the 'culture gap'}

We would also like to know how much the perceived and the preferred cultures fit each other, and, if there is a significant gap between them, which dimensions are responsible for the lack of fit. Since we compared means to each other, the selected method was the paired-samples $t$-test, which is expected to be robust to nonnormality at this sample size (Lumley et al, 2002). The numeric results are presented in the last column of Table 2. In 13 statements out of the total of 20 (65\%), significant mean-differences were identified (at the 5\% significance level). First, we list here those statements in which students would welcome an increase (i.e. the 'now' value was significantly lower than the 'preferred', on average):

- dominant characteristics: controlled and structured (1D),

- behaviour of the faculty staff and the management: mentoring, facilitating $(2 A)$,

- management style: teamwork, and participation (3A), innovation, freedom and uniqueness $(3 B)$,

- the glue holding the faculty together: loyalty and mutual trust (4A), commitment to innovation and development (4B),

- strategic emphases: human development, trust, and participation (5A).

Second, we present the features that the respondents would like to weaken (i.e. the 'now' value was, on average, significantly higher than the 'preferred' value):

- dominant characteristics: competitive, job- and results-oriented (1C),

- behaviour of the faculty staff and the management: aggressive and achievement-oriented (2C),

- management style: hard-driving competitiveness, and achievement (3C),

- the glue holding the faculty together: formal rules and regulations $(4 D)$,

Studia Universitatis "Vasile Goldis" Arad. Economics Series Vol 27 Issue 1/2017

ISSN: 1584-2339; (online) ISSN: $2285-3065$ 
Ujhelyi M., Kun A.I., Hanesz J. (2017)

Students' perception of organization culture at a Faculty of Science and Technology

- strategic emphases: competitive actions and achievement (5C), permanence, stability, efficiency and control (5D).

On the level of culture-types, significant gaps between the ideal and the perceived values were identified in all the four cases (according to the paired samples $t$-tests). An average respondent would welcome an increase in the clan and adhocracy types, and a decrease in the market and hierarchy types.

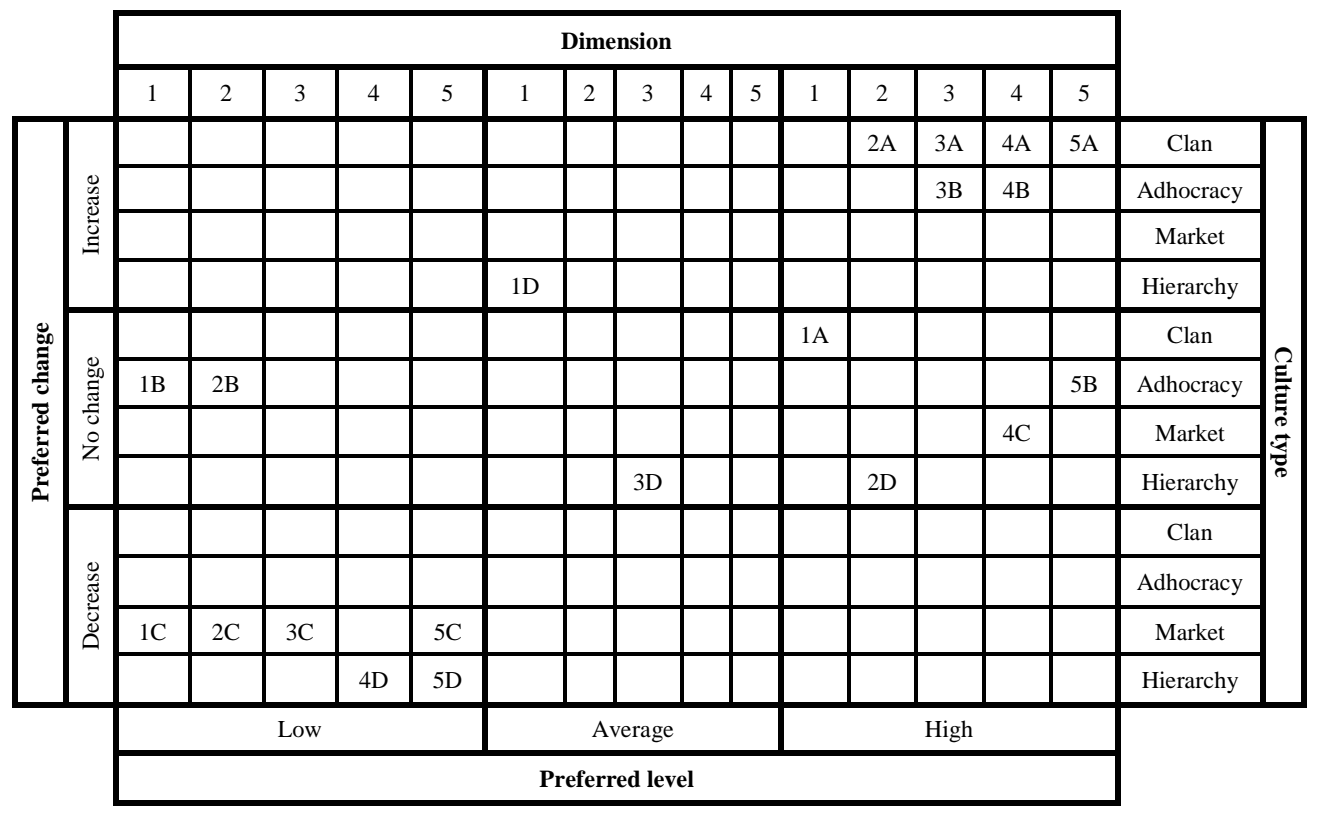

Figure 3. Nine-box diagram of the expected cultural level and change Source: primary research

Figure 3 presents a nine-box matrix that shows the preferred strength of the four culture-types and the perceived gap between the ideal and the present position of these types. We can identify that there is one culture type (market) and six OCAI features $(1 \mathrm{C}, 2 \mathrm{C}, 3 \mathrm{C}, 4 \mathrm{D}, 5 \mathrm{C}, 5 \mathrm{D})$ in the lower left corner box; while another type (clan) and another six features (2A, 3A, 3B, 4A, 4B, 5A) appear in the upper right corner box. In these cases the respondents prefer a low (or high) value which is lower (or higher) than the current level. In the case of adhocracy culture and the 1D statement, the students feel the current value should be increased, but only to an average level from its current below-average 'now' value. Just the opposite is the case with the hierarchy culture, where the desired level is also the average as well, but this time, in order to achieve it, the current value should be lowered. For the 
remaining seven statements $(1 \mathrm{~B}, 2 \mathrm{~B}$ with low preferred value, $3 \mathrm{D}$ with average preferred value, $1 \mathrm{~A}, 2 \mathrm{D}, 4 \mathrm{C}, 5 \mathrm{~B}$ with high preferred value) the current level is considered to be appropriate by the respondents.

\section{Conclusions}

According to the first research question, the diagnosis identified that the students in our sample could not place the Faculty's culture into any of the four types of the Competing Values Framework. The only distinctive feature which they found to be significant (at the 5\% level) is a low level of the adhocracy-culture. We can also note that at a lower level of significance (10\%), the hierarchy was perceived to be higher than in a neutral culture.

We can give a positive answer to the first part of the second research question: i.e. the students did indeed seem to prefer a faculty culture which differs from the present one. We respond to the second, 'how' part of the question, with the following details. In the opinion of the respondents the ideal culture would be high in clan-like features and low in market-like ones (compared to a neutral culture). If we decrease the significance level to $10 \%$, we can also add that the culture would be better if it were weak in hierarchy and strong in adhocracy.

It may be even more interesting for the faculty management that we have identified gaps along all the four culture types (at the 1\% significance level). Clan and adhocracy cultures are perceived as being too low, and the other two types too high, according to the students.

Our findings support some of the conclusions of Ujhelyi and Kun (2016), as the students' 'preferred' culture proved to be differ more from a totally neutral culture than their 'now' culture in this faculty, too, just as was the case in the previously analysed Faculty of Engineering. It was also similar to the earlier research in that the respondents showed a preference for a culture close to the clan and adhocracy types but far from the market and hierarchy types. On the other hand, the 'now' cultures of the two faculties were diagnosed to be different. The latter leads to a conclusion - within the limitations of our research - those students' cultural preferences are very similar, even if they perceive different cultural traits in their institutions.

However, it is very important to note that this research did not reveal the actual organizational culture of the faculty, but only what the students perceived. Moreover, neither does the students' preferred culture necessarily describe the culture the faculty should develop. Thus, the faculty's management should not consider it as an aim. At the same time, our results reveal important information about how the students see the cultural side of their institution, and what features of this culture make them feel comfortable or uncomfortable. The management can 
take this information into consideration when making decisions in connection with student satisfaction.

For the future, an interesting research orientation could be the comparison of student-perceived 'now' and 'preferred' cultures at different faculties within many higher education institutions to explore potential cultural traits connected to faculty-types (e.g. faculties with a business orientation, faculties of arts, engineering-oriented faculties etc.). Expanding the research internationally (involving institutions from more than one country) could also reveal the moderating effect of national cultures.

\section{References}

1. Cameron, Kim S. and Quinn, Robert E. (2006). Diagnosing and Changing Organizational Culture. Based on the Competing Values Framework. The Jossey-Bass Business \& Management Series. Revised Edition.

2. Campbell, John P., Brownas, David A., Peterson, Norman G., and Dunnette, Marvin D. (1974). The Measurement of Organizational Effectiveness: A Review of Relevant Research and Opinion. Minneapolis: Navy Personnel Research and Development Center, Personnel Decisions.

3. Fralinger, Barbara and Olson, Valerie (2007). Organizational Culture At The University Level: A Study Using The OCAI Instrument. Journal of College Teaching \& Learning: Vol. 4, No. 11, pp. 85-97.

4. Handy, Charles (1993). Understanding Organizations. Oxford University Press.

5. Howard, Larry W. (1998), Validating the Competing Values Model as a Representation of Organizational Cultures. International Journal of Organizational Analysis, Vol. 6, No. 3, pp. 231-250.

6. Lumley, Thomas, Diehr, Paula, Emerson, Scott, and Chen, Lu (2002). The importance of the normality assumption in large public health data sets. Annual Review of Public Health: Vol. 23. No. 1, pp. 151-169.

7. Martinez, Elizabeth A., Beaulieu, Nancy, Gibbons, Robert, Pronovost, Peter and Wang, Thomas (2015), Organizational Culture and Performance. American Economic Review: Vol. 105, No. 5, pp. 331-335.

8. Shirbagi, Naser (2007). Egyetemi oktatók szervezeti elkötelezettsége, és annak kapcsolata a szervezeti kulturaval (Organisational commitment of university lecturers, and this commitment's relationship with organisational culture). Magyar Pedagógia, Vol. 107, No. 3, pp. 185-203.

9. Peters, Thomas, and Waterman, Robert H. (1982). In Search of Excellence: Lessons from America's Best-Run Companies. Harper and Row: London.

10. Quinn, Robert E. and Rohrbaugh, John (1983). A Spatial Model of Effectiveness Criteria: towards a competing values approach to organizational analysis, Management Science, Vol. 29, No. 3, pp. 363-377.

11. Schein, Edgar H. (1985). Organizational Culture and Leadership: A Dynamic View. Jossey-Bass: San Francisco, CA. 
Ujhelyi M., Kun A.I., Hanesz J. (2017)

Students' perception of organization culture at a Faculty of Science and Technology

12. Senior, Barbara and Swailes, Stephen (2010). Organizational Change. Fourth Edition, Financial Times Prentice Hall, Pearson Education, Harlow.

13. Slevin, Dennis P. and Covin, Jeffrey G. (1990). Juggling Enterpreneurial and Organizational Structure. How to Get Your Act Together? Sloan Management Review: Vol. 31, No. 2, pp. 43-54.

14. Ujhelyi, Maria and Kun, Andras Istvan (2016): Szervezeti kultura vizsgalata OCAI modellel a Debreceni Egyetem müszaki menedzser hallgatói körében (Examining Organisational Culture with the OCAI model among Technical Management BSc Students at the University of Debrecen). International Journal of Engineering and Management Sciences (IJEMS): Vol. 1, No. 1, pp. 1-8, DOI: 10.21791/IJEMS.2016.1.46. 
Ujhelyi M., Kun A.I., Hanesz J. (2017)

Students' perception of organization culture at a Faculty of Science and Technology

\section{Appendix}

Table 1. The OCAI questionnaire administered to students, adapted to our research with 5 dimensions (translated from Hungarian)

1. The Faculty you are studying at is

Now Preferred

\begin{tabular}{|c|c|c|c|}
\hline$A$ & & & \\
\hline B & & & \\
\hline & $\begin{array}{l}\text {... achievement-oriented. The priority is that all jobs and tasks must be } \\
\text { done. }\end{array}$ & & \\
\hline D & $\begin{array}{l}\text {...controlled and structured (well organised, regulated, and } \\
\text { transparent). }\end{array}$ & & \\
\hline & Total: & 100 & 100 \\
\hline
\end{tabular}

2. The management and the staff of the Faculty

\begin{tabular}{|l|l|c|c|}
\hline A & $\ldots$ are mentoring and facilitating. & & \\
\hline B & $\ldots$ exemplify entrepreneurship and innovation. & & \\
\hline C & $\ldots$ are aggressive and achievement-oriented. & & \\
\hline D & $\ldots$ are cooperative and coordinating. & & \\
\hline \multicolumn{2}{|l|}{ Total: } & 100 & 100 \\
\hline
\end{tabular}

3. The management style of the Faculty is characterised by Now

\begin{tabular}{|c|l|l|l|}
\hline A & ...teamwork and participation. & & \\
\hline B & $\ldots$...innovation, freedom, and uniqueness. & & \\
\hline C & ...hard-driving competitiveness, and achievement. & & \\
\hline D & $\ldots$... conformity, predictability, and stability in relationships. & & \\
\hline
\end{tabular}

4. The glue that holds the Faculty together is Now Preferred

\begin{tabular}{|c|l|c|c|}
\hline A & ...loyalty and mutual trust. & & \\
\hline B & ...commitment to innovation and development. & & \\
\hline C & ...emphasis on achievement and goal accomplishment. & & \\
\hline D & $\ldots$ formal rules and regulations. & & \\
\hline & Total: & 100 & 100 \\
\hline 5. The Faculty puts emphasis on... & Now Preferred \\
\hline
\end{tabular}

\begin{tabular}{|r|l|r|r|}
\hline A & $\begin{array}{l}\text {...human development. A high level of trust and participation are } \\
\text { present. }\end{array}$ & & \\
\hline B & $\begin{array}{l}\ldots \text { acquiring new opportunities and resources, and coping with new } \\
\text { challenges. }\end{array}$ & & \\
\hline C & $\ldots$ competitive actions and achievement. & & \\
\hline D & $\ldots$ permanence and stability. Efficiency and control are important. & & \\
\hline
\end{tabular}

DE GRUYTER OPEN
Studia Universitatis "Vasile Goldis" Arad. Economics Series Vol 27 Issue 1/2017 SSN: 1584-2339; (online) ISSN: 2285 - 3065

Web: publicatii.uvvg.ro/index.php/studiaeconomia.Pages $41-54$ 